\title{
Trends and variations in breast and colorectal cancer incidence from 1995 to 2011: A comparative study between Texas Cancer Registry and National Cancer Institute's Surveillance, Epidemiology and End Results data
}

\author{
ZHEYU LIU $^{1,2}$, YEFEI ZHANG ${ }^{1,2}$, LUISA FRANZIN $^{3}$, JANICE N. CORMIER $^{4}$, \\ WENYAW CHAN ${ }^{2}$, HUA XU ${ }^{5}$ and XIANGLIN L. DU ${ }^{1,3}$ \\ Departments of ${ }^{1}$ Epidemiology, Human Genetics, and Environmental Sciences, \\ ${ }^{2}$ Biostatistics and ${ }^{3}$ Management, Policy and Community Health, School of Public Health, \\ University of Texas Health Science Center; ${ }^{4}$ The University of Texas M.D. Anderson Cancer Center; \\ ${ }^{5}$ The University of Texas School of Biomedical Informatics, Houston, TX, USA
}

Received November 13, 2014; Accepted December 23, 2014

DOI: 10.3892/ijo.2015.2881

\begin{abstract}
Few studies have examined the cancer incidence trends in the state of Texas, and no study has ever been conducted to compare the temporal trends of breast and colorectal cancer incidence in Texas with those of the National Cancer Institute's Surveillance, Epidemiology and End Results (SEER) in the United States. This study aimed to conduct a parallel comparison between the Texas Cancer Registry and the National Cancer Institute's SEER on cancer incidence from 1995 to 2011. A total of 951,899 breast and colorectal cancer patients were included. Age-adjusted breast cancer incidence was 134.74 per 100,000 in Texas and 131.78 per 100,000 in SEER in 1995-2011, whereas age-adjusted colorectal cancer incidence was 50.52 per 100,000 in Texas and 49.44 per 100,000 in SEER. Breast cancer incidence increased from 1995 to 2001, decreased from 2002 to 2006, and then remained relatively stable from 2007 to 2011. For colorectal cancer, the incidence increased in 1995-1997, and then decreased continuously from 1998 to 2011 in Texas and SEER areas. Incidence rates and relative risks by age, gender and ethnicity were identical between Texas and SEER.
\end{abstract}

\section{Introduction}

Breast cancer is the most commonly diagnosed cancer in women in the United States, while colorectal cancer is one of the top three most commonly diagnosed cancers among men

Correspondence to: Dr Xianglin L. Du, Department of Epidemiology, Human Genetics, and Environmental Sciences, University of Texas School of Public Health, 1200 Pressler Street, RAS-E631, Houston, TX 77030, USA

E-mail: xianglin.l.du@uth.tmc.edu

Key words: breast cancer, colorectal cancer, incidence rates, trends, relative risks and women (1-3). It is estimated that there will be 136,830 new colorectal cancer cases and 235,030 new breast cancer cases in 2014 in the USA (4-6). The incidence rates for breast and colorectal cancer have been declining consistently in recent years among all age groups and ethnicities (7-9). The decreasing incidence trends in breast and colorectal cancer have been attributed to earlier detection and more advanced treatment (10-14). Although cancer incidence rates have declined since the early 1990's, the burden of cancer and its complications remains high and has a significant impact on human health (15-17).

A number of studies have examined Surveillance, Epidemiology and End Results (SEER) data for national cancer incidence trends and variations by age, ethnicity, cancer stage and other factors in the USA (18-23). However, the SEER data do not include Texas, a large and diverse state. The Texas Cancer Registry collects data on cancer in Texas. Few studies have examined the cancer incidence trends in the state of Texas (24-26), and no study has ever been conducted to compare the temporal trends of breast and colorectal cancer incidence in Texas with those of SEER. Therefore, in this study, we used the National Cancer Institute's SEER data and Texas Cancer Registry (TCR) data to examine whether the overall incidence trends for both breast and colorectal cancer have similar patterns in the TCR and in SEER areas over the past 17 years from 1995 to $2011(2,27)$. We also examined the variations in cancer incidence rates by age, gender, ethnicity, tumor stage and tumor grade in the TCR and SEER areas. The findings from this parallel comparison are expected to provide a significant overview of cancer incidence trends at the state and national level, and also to identify important factors associated with a decreasing risk of cancer, which are critical to enhance cancer prevention and control.

\section{Materials and methods}

Data sources. The SEER (Surveillance, Epidemiology and End Results) public-use dataset and the TCR (Texas Cancer 
Registry) limited-use dataset were utilized for this study $(2,27)$. The SEER program, supported by the National Cancer Institute, includes population-based tumor registries in selected geographic areas in the USA. Because of our study comparison between the TCR and SEER for cancer cases in 1995 through 2011, we selected the following 9 SEER areas: Atlanta, Connecticut, Detroit, Hawaii, Iowa, New Mexico, San Francisco-Oakland, Seattle-Puget Sound and Utah, accounting for $\sim 9.4 \%$ of the USA population (2). By the year of 2010, there were 18 SEER registries that covered $26.2 \%$ of the USA population (2). Because our study aimed to compare the incidence trends in breast and colorectal cancer from 1995 to 2011, only these nine registries, which had complete records on tumor stage and tumor grade in the study period, were included. The SEER registries ascertain all newly diagnosed (incident) cancer cases from multiple reporting sources such as hospitals, outpatient clinics, laboratories, private medical practitioners, nursing/convalescent homes/ hospices, autopsy reports and death certificates (2). The TCR is a statewide and population-based cancer registry and is Gold Certified by the North American Association of Central Cancer Registries (27). The TCR dataset was determined to cover at least $95 \%$ statewide data for all cancer cases diagnosed from 1995 through 2011 in Texas. The denominator of population data used to calculate incidence rates were acquired from the U.S. Census Bureau's Population Estimates Program (28). The Committee for the Protection of Human Subjects at the University of Texas Health Science Center in Houston approved this study.

Study population. We identified all women diagnosed with breast cancer and men and women diagnosed with colorectal cancer as their primary tumor in 1995-2011 from both SEER and TCR. In the 9 SEER registries, 328,142 patients with breast cancer and 224,511 patients with colorectal cancer were included. In Texas, 243,695 women with breast cancer and 155,551 patients with colorectal cancer were included.

Study variables. The primary outcome of interest was the incidence rates of breast and colorectal cancer from 1995 to 2011. Incidence rates were defined as the number of new cases in one calendar year divided by the total population at risk in the same year (29). Breast cancer cases were identified using the 'Primary Site' variable in both SEER and TCR, coded as C500-C509 according to 'International Classification of Diseases for Oncology, Third Edition (ICD-O-3), and Topography Section $(2,7)^{\prime}$. Colorectal cancer cases were coded as C180-C189, C199, C209, and C260 (2). According to the methods by Wu et al in counting total colorectal cancer cases, colon included the cecum (C180), appendix (C181), ascending colon (C182), hepatic flexure (C183), transverse colon (C184), splenic flexure (C185), descending colon (C186), sigmoid colon (C187), and large intestine, NOS(C188-C189,C260) (30). The rectum included the rectosigmoid junction (C199) and the rectum-not otherwise specified (C209).

The independent variables of interest in this study included age, gender, ethnicity, tumor stage and tumor grade. Age was classified according to five categories with $<50,50-59,60-69$, $70-79$ and $\geq 80$ years. Gender was a binary variable with male and female, but for breast cancer, only women were included because of the rarity of diagnosis in men. Ethnicity was categorized as white, black and other. Tumor stage was classified as localized, regional, distant and unknown. Localized stage was confined within the breast and colon. Regional stage was defined as tumor involvement of the regional lymph nodes, primarily those in the axilla, to be involved. Distant stage was defined as the cancer metastatic to other parts of the body as well. The unknown stage was defined as having missing information of cancer status (31). Tumor grade represented the level of differentiation, in which poorly differentiated cancer cells usually divide more quickly and therefore represent more aggressive malignancies (32). Tumor grade at diagnosis was stratified into four categories: differentiated, moderately differentiated, poorly differentiated and undetermined.

Statistical analysis. Annual incidence rates of breast and colorectal cancer cases per 100,000 persons were age-adjusted to the 2000 US standard population stratified by five age groups. The incidence rates were computed by age-group, gender, race, tumor stage, and tumor grade for breast and colorectal cancer separately. We used the SEER ${ }^{*}$ Stat software to calculate incidence rates by dividing the number of new cancer cases in each category over the total population at risk (33). The SAS statistical software was used to calculate incidence rates with 95\% confidence intervals for TCR data. Poisson regression model with population size specific to demographic groups as offset variable were used to determine the association between incidence rates and potential risk factors. Covariates included age-group, gender, race, tumor stage and tumor grade. In order to determine the temporal relationship, risk ratios between two cancer incidence rates were calculated and adjusted by potential confounders. The assumption of the Poisson model were examined by examining constant variance plots of the variables. No specific pattern was detected in the outputs indicating that the constant variance was valid.

\section{Results}

Table I presents the total number of patients diagnosed with breast and colorectal cancer in Texas and in 9 SEER areas. From 1995 to 2011, there were 243,695 new breast cancer cases and 155,551 colorectal cancer cases in Texas, and 328,142 breast cancer cases and 224,511 colorectal cancer cases in 9 SEER areas. The mean age for breast cancer was 60.5 years in the TCR and 61.7 years in SEER, and the mean age for colorectal cancer was 67.2 years in the TCR and 69.2 years in SEER. The age distribution of these cancer cases was similar overall in the TCR and SEER, although the proportion of younger patients appeared to be slightly higher in Texas. Over $50 \%$ of new breast cancer cases occurred in those aged $\geq 60$ years, while $>70 \%$ of new colorectal cancer cases occurred in those aged $\geq 60$ years. There were a slightly more male colorectal cancer cases in the TCR and SEER, and $>80 \%$ of patients were white. The overall distribution by tumor stage and tumor grade was similar between Texas and SEER, but the proportion of cancer cases with unknown tumor stage and undetermined tumor grade was higher in the TCR than that in SEER.

Fig. 1 presents parallel comparisons of age-adjusted incidence trends from 1995 to 2011 for breast cancer between the 
Table I. Number (proportion) of patients with breast and CRC in the Texas Cancer Registry (TCR) and SEER, 1995-2011, stratified by patient and tumor factors.

\begin{tabular}{|c|c|c|c|c|}
\hline \multirow[b]{2}{*}{ Patient and tumor characteristics } & \multicolumn{4}{|c|}{ No. $(\%)$ of cancer cases } \\
\hline & $\operatorname{TCR}(\%)$ & SEER $(\%)$ & TCR $(\%)$ & SEER $(\%)$ \\
\hline Mean age & 60.46 & 61.73 & 67.15 & 69.16 \\
\hline \multicolumn{5}{|l|}{ Age (years) } \\
\hline$<50$ & $60017(24.63)$ & $74066(22.57)$ & $17359(11.16)$ & $20190(8.99)$ \\
\hline $50-59$ & $59481(24.41)$ & $76676(23.37)$ & $28088(18.06)$ & $35423(15.78)$ \\
\hline $60-69$ & $55660(22.84)$ & $72686(22.15)$ & $37406(24.05)$ & $48532(21.62)$ \\
\hline $70-79$ & $43744(17.95)$ & $62866(19.16)$ & $40976(26.34)$ & $62987(28.06)$ \\
\hline$\geq 80$ & 24793 (10.17) & $41848(12.75)$ & $31722(20.39)$ & $57379(25.56)$ \\
\hline \multicolumn{5}{|l|}{ Gender } \\
\hline Male & & & $82571(53.08)$ & $113388(50.50)$ \\
\hline Female & 243695 & $328142 \quad(100)$ & $72980(46.92)$ & $111123(49.50)$ \\
\hline \multicolumn{5}{|l|}{ Race/ethnicity } \\
\hline White & $210903(86.54)$ & $269958(82.65)$ & $132793(85.37)$ & $181261(81.14)$ \\
\hline Black & 26161 (10.74) & $30525 \quad(9.35)$ & $19428(12.49)$ & $22513(10.08)$ \\
\hline $\begin{array}{l}\text { Other (American Indian/ } \\
\text { Asian/Pacific Islander) }\end{array}$ & $6631 \quad(2.72)$ & $26135 \quad(8.00)$ & $3330 \quad(2.14)$ & 19609 (8.78) \\
\hline \multicolumn{5}{|l|}{ Tumor stage } \\
\hline Localized & $149999(61.55)$ & $207998(63.39)$ & $57800(37.16)$ & 88825 (39.56) \\
\hline Regional & $61325(25.16)$ & 96063 (29.27) & $52374(33.67)$ & $81824(36.45)$ \\
\hline Distant & 11567 & $15808 \quad(4.82)$ & 26594 (17.10) & $41776(18.61)$ \\
\hline Unknown & $20804 \quad(8.54)$ & $8273 \quad(2.52)$ & $18783(12.08)$ & $12086(5.38)$ \\
\hline \multicolumn{5}{|l|}{ Tumor grade } \\
\hline I: Well differentiated & $34324(14.08)$ & $63902(19.47)$ & $11562(7.43)$ & $18962(8.45)$ \\
\hline II: Moderately differentiated & $77260(31.70)$ & $123943(37.77)$ & $84543(54.35)$ & $128657(57.31)$ \\
\hline III: Poorly differentiated & 75475 (30.97) & $100962(30.77)$ & $23173(14.90)$ & $36499(16.26)$ \\
\hline IV: Undetermined & $56636(23.24)$ & 39335 (11.99) & $36273(23.32)$ & $40393(17.99)$ \\
\hline Total & 243695 & 328142 & 155551 & 224511 \\
\hline
\end{tabular}

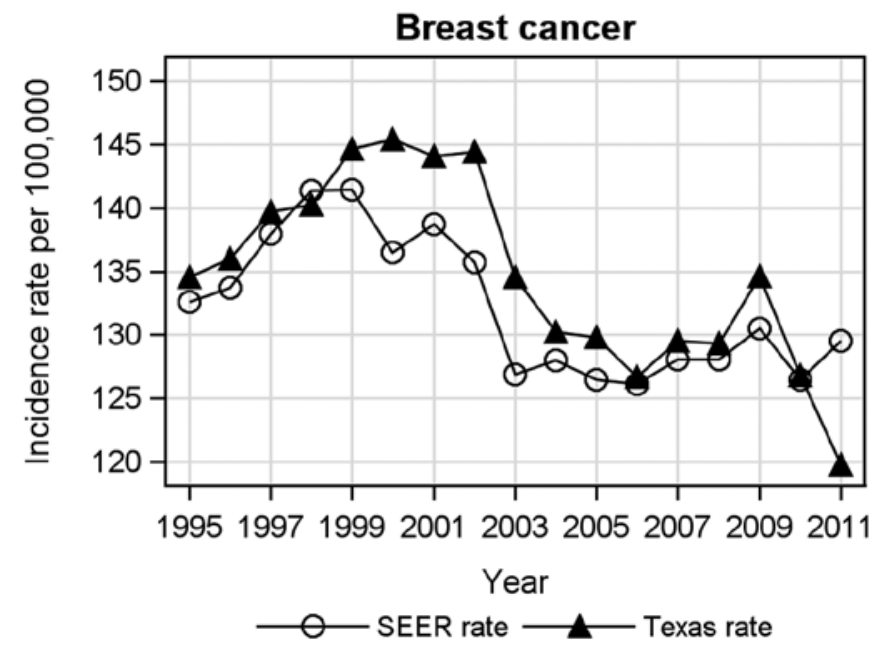

Figure 1. Breast cancer age-adjusted incidence rates over time by year (1995-2011).

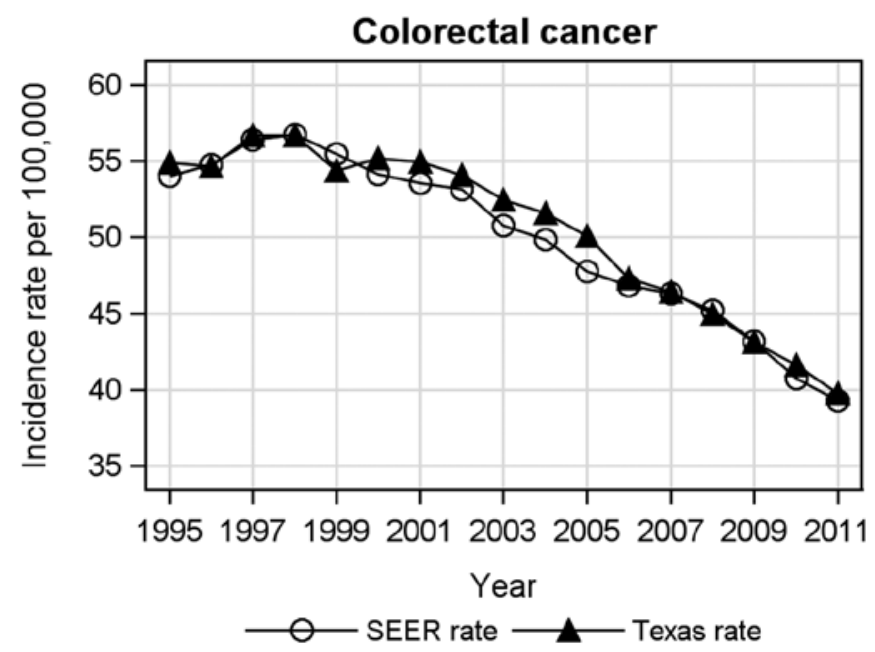

Figure 2. Colorectal cancer age-adjusted incidence rates over time by year (1995-2011). 

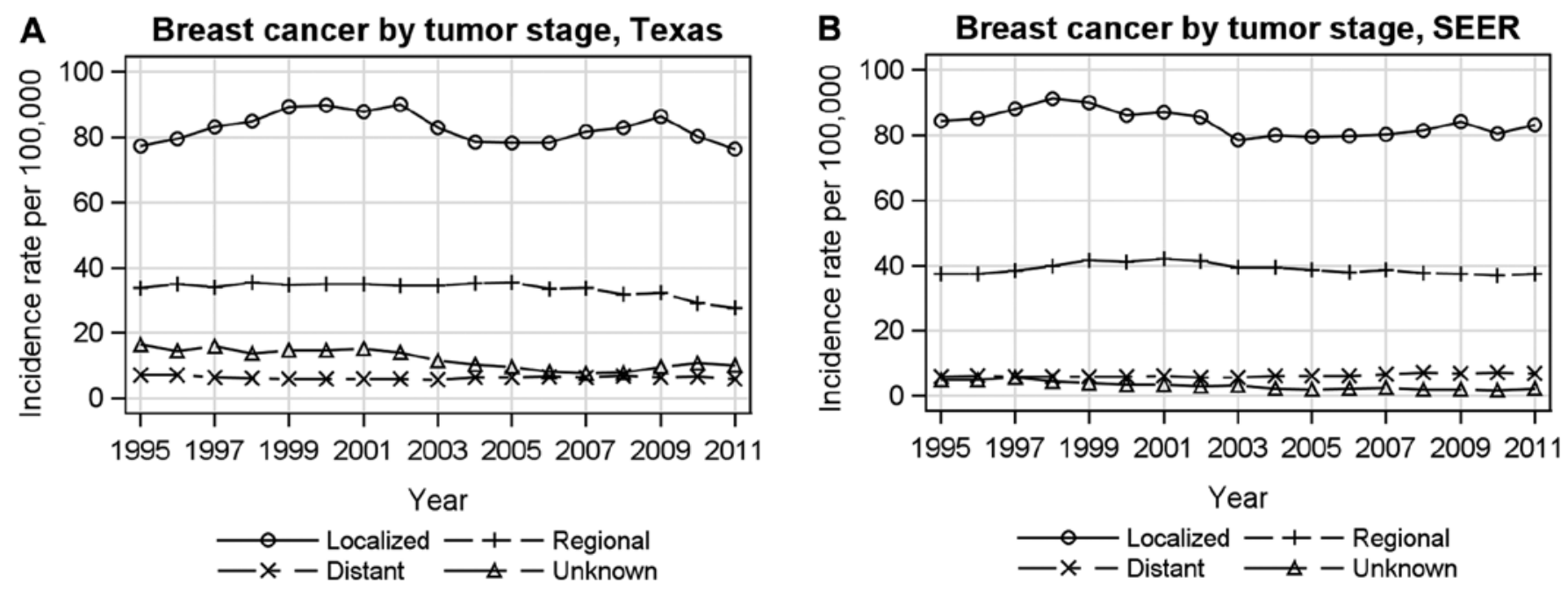

Figure 3. Breast cancer age-adjusted incidence rates over time by tumor stage, 1995-2011. (A) Texas. (B) SEER.
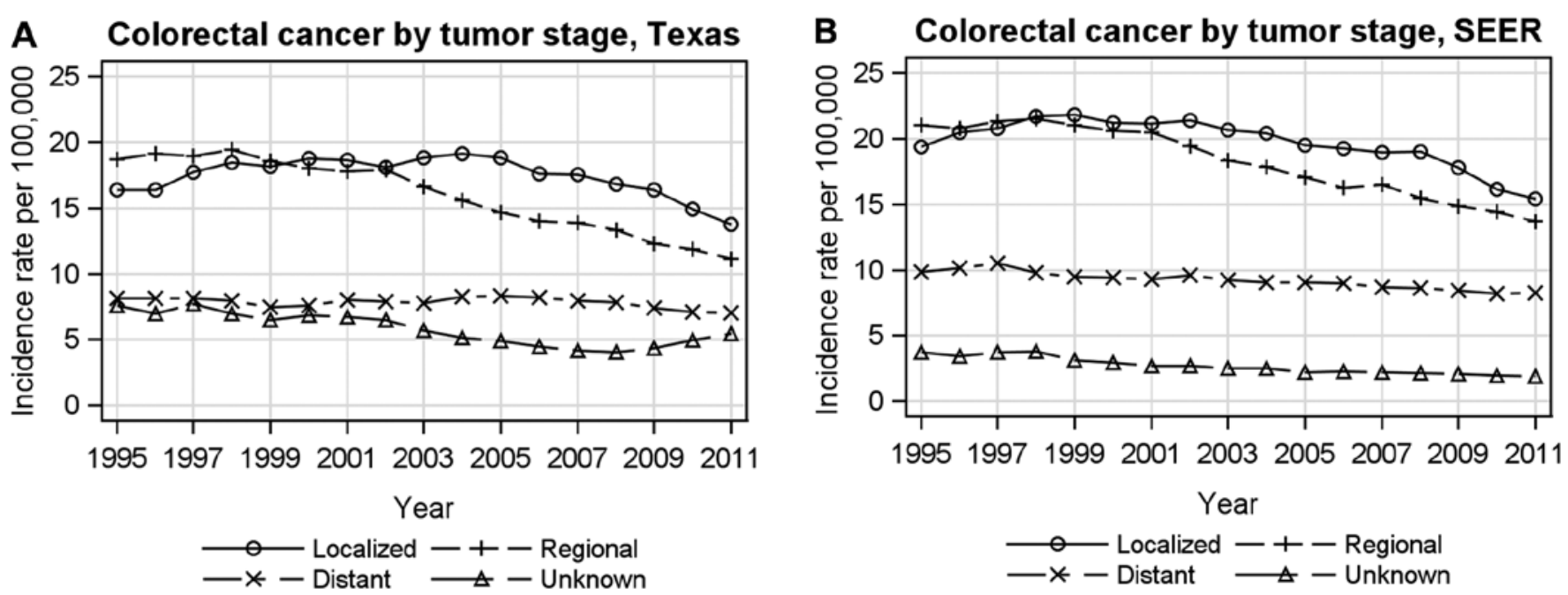

Figure 4. Colorectal cancer age-adjusted incidence rates over time by tumor stage, 1995-2011. (A) Texas. (B) SEER.

TCR and SEER areas, whereas Fig. 2 presents the age-adjusted incidence trends from 1995 to 2011 for colorectal cancer in the TCR as compared to SEER. The overall incidence trends and changing patterns over the 17-year periods for breast and colorectal cancer were almost identical between the TCR and SEER areas. Specifically, breast cancer incidence increased from 1995 to 2001, decreased from 2002 to 2006, and then remained relatively stable from 2007 to 2011 (Fig. 1). The increased breast cancer incidence in 1995-2001 was consistent with the time period when the widespread use of screening program was implemented (34). For colorectal cancer, the incidence increased in the first three years between 1995 and 1997, and then decreased continuously from 1998 to 2011 in both Texas and SEER areas.

Figs. 3 and 4 present the age-adjusted tumor stage-specific incidence rates for breast and colorectal cancer in the TCR and SEER. For breast cancer, tumor stage-specific incidence rates were similar between the TCR (Fig. 3A) and SEER (Fig. 3B), in which incidence for localized breast cancer increased early on and then decreased, while the incidence for distant stage breast cancer was stable with a slight increase over time. For colorectal cancer, the incidence for all stages decreased over time in the TCR (Fig. 4A) and in SEER (Fig. 4B) except for an increase for unknown stage colorectal cancer in the TCR from 2008 to 2011.

Table II presents the age-adjusted incidence rates of breast cancer and the relative risks of cancer incidence by patient and tumor characteristics in the TCR and SEER. The overall age-adjusted breast cancer incidence in 1995-2011 was 134.74 per 100,000 in the TCR and 131.78 per 100,000 in SEER. The specific incidence rates and relative risks by age, gender and ethnicity were also similar between in the TCR and SEER after adjusting for tumor stage and grade. For example, as compared to those $<50$ years of age, women $\geq 60$ were $>9$ times more likely to develop breast cancer, whereas American Indians and Asian-Pacific Islanders were significantly less likely to develop breast cancer and African Americans had a marginally lower risk of developing breast cancer as compared to whites. 
Table II. Age-adjusted incidence rates of breast cancer in the Texas Cancer Registry (TCR) and in SEER, $1995-2011$.

\begin{tabular}{|c|c|c|c|c|}
\hline \multirow[b]{2}{*}{ Characteristics } & \multicolumn{2}{|c|}{ Breast cancer in TCR } & \multicolumn{2}{|c|}{ Breast cancer in SEER } \\
\hline & Incidence $(95 \% \mathrm{CI})^{\mathrm{a}}$ & $\mathrm{RR}(95 \% \mathrm{CI})^{\mathrm{b}}$ & Incidence $(95 \% \mathrm{CI})^{\mathrm{a}}$ & $\mathrm{RR}(95 \% \mathrm{CI})^{\mathrm{b}}$ \\
\hline \multicolumn{5}{|l|}{ Age (years) } \\
\hline$<50$ & $43.03(42.24-43.82)$ & 1.00 (Reference) & $44.17 \quad(43.85-44.49)$ & 1.00 (Reference) \\
\hline $50-59$ & $287.02(274.65-299.38)$ & $6.58(6.50-6.65)$ & $267.75(265.86-269.66)$ & $6.16(6.10-6.23)$ \\
\hline $60-69$ & $405.00(392.57-417.44)$ & $9.34 \quad(9.23-9.45)$ & $394.61(391.75-397.50)$ & $9.29 \quad(9.20-9.39)$ \\
\hline $70-79$ & $461.24(444.70-477.78)$ & $10.63(10.50-10.76)$ & $463.28(459.66-466.92)$ & $11.74(11.62-11.87)$ \\
\hline$\geq 80$ & $404.07(389.27-418.87)$ & $9.27 \quad(9.14-9.41)$ & $419.42(415.40-423.46)$ & $12.06(11.91-12.20)$ \\
\hline \multicolumn{5}{|l|}{ Race/ethnicity } \\
\hline White & $136.14(131.91-140.37)$ & 1.00 & $136.45(135.93-136.97)$ & 1.00 \\
\hline Black & $131.90(129.40-134.40)$ & $0.98 \quad(0.97-0.99)$ & $123.33(121.93-124.75)$ & $0.93 \quad(0.92-0.94)$ \\
\hline $\begin{array}{l}\text { Other (American Indian/ } \\
\text { Asian/Pacific Islander) }\end{array}$ & $98.51 \quad(89.74-107.27)$ & $0.77 \quad(0.75-0.79)$ & $96.75 \quad(95.58-97.94)$ & $0.72 \quad(0.71-0.73)$ \\
\hline Total & $134.74(130.88-138.60)$ & & $131.78(131.32-132.23)$ & \\
\hline
\end{tabular}

${ }^{a}$ Incidence rate was number of cases per 100,000 population and was age adjusted to the 2000 US population (28). ${ }^{b}$ Incidence ratio (relative risk) was adjusted for age, race, tumor stage and tumor grade.

Table III. Age-adjusted incidence rates of CRC in the Texas Cancer Registry (TCR) and in SEER, 1995-2011.

\begin{tabular}{|c|c|c|c|c|}
\hline \multirow[b]{2}{*}{ Characteristics } & \multicolumn{2}{|c|}{ Colorectal cancer in TCR } & \multicolumn{2}{|c|}{ Colorectal cancer in SEER } \\
\hline & Incidence $(95 \% \mathrm{CI})^{\mathrm{a}}$ & $\mathrm{RR}(95 \% \mathrm{CI})^{\mathrm{b}}$ & Incidence $(95 \% \mathrm{CI})^{\mathrm{a}}$ & $\mathrm{RR}(95 \% \mathrm{CI})^{\mathrm{b}}$ \\
\hline \multicolumn{5}{|l|}{ Age (years) } \\
\hline$<50$ & $6.11 \quad(5.92-6.30)$ & 1.00 (Reference) & $(5.95-6.12)$ & 1.00 (Reference) \\
\hline $50-59$ & $68.46 \quad(67.00-69.92)$ & $11.29(11.07-11.50)$ & $63.13 \quad(62.47-63.79)$ & $10.60(10.42-10.79)$ \\
\hline $60-69$ & $145.38(137.06-153.69)$ & $23.76(23.33-24.19)$ & $139.91(138.67-141.16)$ & $23.37(22.98-23.76)$ \\
\hline $70-79$ & $245.37(225.95-264.79)$ & $41.05(40.33-41.79)$ & $262.84(260.79-264.90)$ & $45.09(44.38-45.82)$ \\
\hline$\geq 80$ & $342.33(314.44-370.23)$ & $58.68(57.60-59.78)$ & $371.32(368.29-374.37)$ & $65.51(64.46-66.59)$ \\
\hline \multicolumn{5}{|l|}{ Gender } \\
\hline Male & $60.78 \quad(57.26-64.29)$ & 1.00 & $57.49 \quad(57.15-57.83)$ & 1.00 \\
\hline Female & $42.70 \quad(40.18-45.21)$ & $0.70 \quad(0.69-0.71)$ & $43.12 \quad(42.87-43.38)$ & $0.75 \quad(0.74-0.76)$ \\
\hline \multicolumn{5}{|l|}{ Race/ethnicity } \\
\hline White & $49.37 \quad(46.52-52.22)$ & 1.00 & $48.87 \quad(48.65-49.10)$ & 1.00 \\
\hline Black & $64.84 \quad(61.68-67.99)$ & $1.35 \quad(1.33-1.37)$ & $58.43 \quad(57.65-59.22)$ & $(1.19-1.22)$ \\
\hline $\begin{array}{l}\text { Other (American Indian/ } \\
\text { Asian/Pacific Islander) }\end{array}$ & $36.69 \quad(33.71-39.67)$ & $0.75 \quad(0.72-0.77)$ & $42.67 \quad(42.07-43.27)$ & $(0.86-0.89)$ \\
\hline Total & $50.52 \quad(47.67-53.38)$ & & $49.44 \quad(49.23-49.64)$ & \\
\hline
\end{tabular}

${ }^{\mathrm{a}}$ Incidence rate was number of cases per 100,000 population and was age adjusted to the 2000 US population (28). ${ }^{\mathrm{b}}$ Incidence ratio (relative risk) was adjusted for age, gender, race, tumor stage and tumor grade.

Similarly, Table III presents the age-adjusted incidence rates of colorectal cancer and relative risks of cancer incidence stratified by patient characteristics in the TCR and SEER after adjusting for tumor stage and grade. Overall age adjusted colorectal cancer incidence rate from 1995 to 2011 was 50.52 per 100,000 in the TCR and 49.44 per 100,000 in SEER. 
Because the mean age for developing colorectal cancer was older than that for breast cancer, those aged 60-69 years were $>23$ times more likely to develop colorectal cancer and those aged $\geq 80$ years were $>58$ times more likely to develop this disease than those $<50$ years of age. The risk of developing colorectal cancer was noted to be significantly lower in women than in men. African Americans had a higher risk of developing colorectal cancer as compared to whites.

\section{Discussion}

This parallel comparison study between the TCR and SEER reported a number of significant findings. The overall incidence trends for both breast and colorectal cancer were noted to have similar patterns from 1995 to 2011. The breast and colorectal cancer incidence rates by age, gender, ethnicity, tumor stage and tumor grade in the TCR were also similar to those in SEER areas. These cancer incidence trends over time and variations by other factors are important findings when monitoring cancer progress, assessing the success of cancer prevention and control, and identifying high-risk populations for additional intervention. Furthermore, the identical cancer incidence trends reported in this comparative study can also be viewed as important evidence of the validity of the TCR's incidence data. This is because the National Cancer Institute's SEER has been established since 1973 and is often considered the gold standard in cancer registries (2).

This study demonstrated that breast cancer incidence increased from 1995 to 2001, decreased from 2002 to 2006, and then was relatively stable from 2007 to 2011. The interval of increased breast cancer incidence was consistent with the time period when widespread use of early detection for breast cancer such as screening mammography programs were implemented. According to a study by Swan et al, the increased use of mammography during the late 1990 's resulted in a dramatically increased number of breast cancer cases among females in the USA (35). Many other studies also supported this finding $(36,37)$. After the peak time increase in 2001, breast cancer incidence continued to decline and became relatively stable over the past several years. A number of studies have suggested that the decreased incidence rates may be attributable to reduction in the use of peri-menopausal hormone therapy, decreases in utilization of mammography and decreases in the number of preclinical cases detected by screening in recent years (38-44).

Similarly, we found that colorectal cancer incidence increased from 1995 to 1997 and then continued to decrease from 1998 to 2011 in both the TCR and SEER areas. We did not observe any dramatically increasing trend period associated with colorectal cancer screening. Several previous studies have reported similar findings and conclusions $(7,8,29)$. This may be related to the nature and gradual adoption of screening tools for colorectal cancer over time $(13,14)$. The U.S. Preventive Service Task Force has recommended that fecal occult blood testing and sigmoidoscopy be used for colorectal cancer screening since the 1990s for persons aged $\geq 50$ (45). The federal Medicare program began covering the cost of colonoscopy screening for colorectal cancer since 2001 for individuals with an average-risk of developing colorectal cancer (46). Colorectal cancer is known to occur later in life with a mean age at 70 years (68 for men and 72 for women) $(47,48)$. We found that men had a higher risk of developing colorectal cancer than women in both the TCR and SEER. Our finding is consistent with the study by Cook et al who concluded that males had much higher risk (RR, 1.36) for colorectal cancer than females from 1995 to 2004 (49). Differences in colorectal cancer incidence rates stratified by ethnicity can largely be explained by differences in education level, smoking status and health insurance status (50-55). In our analysis, the black population had highest colorectal cancer incidence rates. Possible explanations include a larger percentage of the smoking population in blacks; the highest prevalence of cigarette smoking is also known to occur among individuals with high school or lower education (56-58).

Although TCR and SEER datasets are known to be comprehensive and of high quality, a number of factors may have affected the findings. First, we were unable to verify specific populations by year in each registry, which might have resulted in biased calculations for the annual incidence rates. Second, we studied the 9 SEER areas that accounted for $\sim 9 \%$ of the USA population, and therefore the results may not be generalizable to all SEER areas or to the entire USA population. Furthermore, a number of important known risk factors for breast and colorectal cancer such as smoking, family history, physical exercise and environmental factors are not included in these datasets and cannot be studied. The differences in these factors may have affected the cancer incidence comparisons.

In conclusion, breast and colorectal cancer incidence trends from 1995 to 2011 were almost identical between the TCR and SEER areas. Breast cancer incidence increased in 1995-2001 and decreased afterwards, while colorectal cancer incidence decreased continuously from 1998 to 2011. Older age was a significant risk factor for the high risk of developing cancer, particularly for colorectal cancer. The cancer risk also varied according to gender and race/ethnicity. Additional studies may be needed to explore smaller geographical areas within these registries and environmental factors associated with the changing incidence trends.

\section{Acknowledgements}

This study was supported by a grant from the Cancer Prevention and Research Institute of Texas (RP130051). We acknowledge the efforts of the Texas Cancer Registry and the National Cancer Institute in the creation of these databases. The interpretation and reporting of these data are the sole responsibilities of the authors.

\section{References}

1. Siegel R, Ward E, Brawley O and Jemal A: Cancer statistics, 2011. CA Cancer J Clin 61: 212-236, 2011.

2. National Cancer Institute: Surveillance, Epidemiology, and End Results (SEER): SEER limited-use data, 1973-2011 (9 registries databases). http://seer.cancer.gov. Accessed May 29, 2014.

3. DeSantis C, Siegel R, Bandi P and Jemal A: Breast cancer statistics, 2011. CA Cancer J Clin 61: 408-418, 2011.

4. Siegel R, Ma J, Zou Z and Jemal A: Cancer statistics, 2014. CA Cancer J Clin 64: 9-29, 2014.

5. Siegel R, DeSantis C and Jemal A: Colorectal cancer statistics, 2014. CA Cancer J Clin 64: 104-117, 2014. 
6. American Cancer Society: Cancer facts and figures 2014, Atlanta. http://www.cancer.org/. Accessed July 29, 2014.

7. Edwards BK, Ward E, Kohler BA, et al: Annual report to the nation on the status of cancer, 1975-2006, featuring colorectal cancer trends and impact of interventions (risk factors, screening, and treatment) to reduce future rates. Cancer 116: 544-573, 2010

8. Ries LA, Wingo PA, Miller DS, et al: The annual report to the nation on the status of cancer, 1973-1997, with a special section on colorectal cancer. Cancer 88: 2398-2424, 2000.

9. Bray F, McCarron P and Parkin DM: The changing global patterns of female breast cancer incidence and mortality. Breast Cancer Res 6: 229-239, 2004

10. Berry DA, Cronin KA, Plevritis SK, et al: Effect of screening and adjuvant therapy on mortality from breast cancer. N Engl J Med 353: 1784-1792, 2005.

11. Coughlin SS, Costanza ME, Fernandez ME, et al: CDC-funded intervention research aimed at promoting colorectal cancer screening in communities. Cancer 107 (Suppl 5): 1196-1204, 2006.

12. Cheng L, Eng C, Nieman LZ, Kapadia AS and Du XL: Trends in colorectal cancer incidence by anatomic site and disease stage in the united states from 1976 to 2005. Am J Clin Oncol 34: 573-580, 2011

13. Wulfkuhle JD, Liotta LA and Petricoin EF: Proteomic applications for the early detection of cancer. Nat Rev Cancer 3: $267-275,2003$

14. McKean-Cowdin R, Feigelson HS, Ross RK, Pike MC and Henderson BE: Declining cancer rates in the 1990s. J Clin Oncol 18: 2258-2268, 2000.

15. Weir HK, Thun MJ, Hankey BF, et al: Annual report to the nation on the status of cancer, 1975-2000, featuring the uses of surveillance data for cancer prevention and control. J Natl Cancer Inst 95: 1276-1299, 2003

16. Jemal A, Clegg LX, Ward E, et al: Annual report to the nation on the status of cancer, 1975-2001, with a special feature regarding survival. Cancer 101: 3-27, 2004.

17. Ghafoor A, Jemal A, Ward E, Cokkinides V, Smith R and Thun M: Trends in breast cancer by race and ethnicity. CA Cancer J Clin 53: 342-355, 2003.

18. Pruitt SL, Shim MJ, Mullen PD, Vernon SW and Amick BC III: Association of area socioeconomic status and breast, cervical, and colorectal cancer screening: a systematic review. Cancer Epidemiol Biomarkers Prev 18: 2579-2599, 2009.

19. Berry J, Bumpers K, Ogunlade V, et al: Examining racial disparities in colorectal cancer care. J Psychosoc Oncol 27: 59-83, 2009.

20. White A, Liu C, Xia R, et al: Racial disparities and treatment trends in a large cohort of elderly african americans and caucasians with colorectal cancer, 1991 to 2002. Cancer 113 3400-3409, 2008.

21. Fowble BL, Schultz DJ, Overmoyer B, et al: The influence of young age on outcome in early stage breast cancer. Int J Radiat Oncol Biol Phys 30: 23-33, 1994.

22. Chlebowski RT, Chen Z, Anderson GL, et al: Ethnicity and breast cancer: Factors influencing differences in incidence and outcome. J Natl Cancer Inst 97: 439-448, 2005.

23. De Bruijn K, Arends L, Hansen B, Leeflang S, Ruiter R and van Eijck C: Systematic review and meta-analysis of the association between diabetes mellitus and incidence and mortality in breast and colorectal cancer. Br J Surg 100: 1421-1429, 2013.

24. Coyle YM, Hynan LS, Euhus DM and Minhajuddin AT: An ecological study of the association of environmental chemicals on breast cancer incidence in texas. Breast Cancer Res Treat 92 107-114, 2005

25. Coyle YM, Minahjuddin AT, Hynan LS and Minna JD: An ecological study of the association of metal air pollutants with lung cancer incidence in texas. J Thorac Oncol 1: 654-661, 2006.

26. Whitworth KW, Symanski E and Coker AL: Childhood lymphohematopoietic cancer incidence and hazardous air pollutants in southeast texas, 1995-2004. Environ Health Perspect 116: $1576-1580,2008$.

27. Texas Cancer Registry: Epidemiology and Surveillance branch, Texas Department of State Health Services, 211 E. 7th street, suite 325, Austin, TX 78701. http://www.dshs.state.tx.us/tcr/ default.shtm/. Accessed May 28, 2014.

28. U.S. Census Bureau: American community survey (ACS), 2014 http://www.census.gov/topics/population/. Accessed June 11, 2014.
29. Ries L, Melbert D, Krapcho M, et al: SEER cancer statistics review, 1975-2005. Bethesda, MD: National Cancer Institute. 1975-2005, 2008

30. Wu XC, Chen VW, Steele B, et al: Subsite-specific incidence rate and stage of disease in colorectal cancer by race, gender, and age group in the united states, 1992-1997. Cancer 92: 2547-2554, 2001.

31. Ries LAG, Fritz AG and Hurlbut A: SEER summary staging manual-2000: codes and coding instructions. National Cancer Institute, SEER Program, NIH Pub. 62-84, 2007.

32. Klassen AC, Curriero F, Kulldorff M, Alberg AJ, Platz EA and Neloms ST: Missing stage and grade in Maryland prostate cancer surveillance data, 1992-1997. Am J Prev Med 30: S77-S87, 2006.

33. National Cancer Institute: Surveillance epidemiology and end results (SEER). surveillance research program, National Cancer Institute SEER Stat software. Updated version 8.1.5, 2014.

34. Smith RA, Saslow D, Sawyer KA, et al: American Cancer Society guidelines for breast cancer screening: update 2003. CA Cancer J Clin 53: 141-169, 2003.

35. Swan J, Breen N, Coates RJ, Rimer BK and Lee NC: Progress in cancer screening practices in the United States. Cancer 97: $1528-1540,2003$

36. Jorgensen KJ and Gotzsche PC: Overdiagnosis in publicly organised mammography screening programmes: systematic review of incidence trends. BMJ 339: b2587, 2009.

37. Miller BA, Feuer EJ and Hankey BF: Recent incidence trends for breast cancer in women and the relevanceof early detection: an update. CA Cancer J Clin 43: 27-41, 1993.

38. Althuis MD, Dozier JM, Anderson WF, Devesa SS and Brinton LA: Global trends in breast cancer incidence and mortality 1973-1997. Int J Epidemiol 34: 405-412, 2005.

39. Ravdin PM, Cronin KA, Howlader N, et al: The decrease in breast-cancer incidence in 2003 in the United States. N Engl J Med 356: 1670-1674, 2007.

40. Cronin KA, Ravdin PM and Edwards BK: Sustained lower rates of breast cancer in the united states. Breast Cancer Res Treat 117: 223-224, 2009.

41. Glass AG, Lacey JV Jr, Carreon JD and Hoover RN: Breast cancer incidence, 1980-2006: combined roles of menopausal hormone therapy, screening mammography, and estrogen receptor status. J Natl Cancer Inst 99: 1152-1161, 2007.

42. Breen N, A Cronin K, Meissner HI, et al: Reported drop in mammography. Cancer 109: 2405-2409, 2007.

43. Jemal A, Ward E and Thun MJ: Recent trends in breast cancer incidence rates by age and tumor characteristics among U.S. women. Breast Cancer Res 9: R28, 2007.

44. Pelucchi $\mathrm{C}$, Levi $\mathrm{F}$ and La Vecchia $\mathrm{C}$ : The rise and fall in menopausal hormone therapy and breast cancer incidence. Breast 19: 198-201, 2010.

45. U.S. Preventive Services Task Force: Screening for colorectal cancer: U.S. preventive services task force recommendation statement. Ann Intern Med 149: 627-637, 2008.

46. Gross CP, Andersen MS, Krumholz HM, McAvay GJ, Proctor D and Tinetti ME: Relation between medicare screening reimbursement and stage at diagnosis for older patients with colon cancer. JAMA 296: 2815-2822, 2006.

47. Slater G, Papatestas AE, Tartter PI, Mulvihill M and Aufses AH Jr: Age distribution of right- and left-sided colorectal cancers. Am J Gastroenterol 77: 63-66, 1982.

48. American Cancer Society: Colorectal cancer facts \& figures 2011-2013, Atlanta. http://www.cancer.org/acs/groups/content/@ epidemiologysurveilance/documents/document/acspc-028312.pdf. Accessed July 8, 2014.

49. Cook MB, Dawsey SM, Freedman ND, et al: Sex disparities in cancer incidence by period and age. Cancer Epidemiol Biomarkers Prev 18: 1174-1182, 2009.

50. Goel MS, Wee CC, McCarthy EP, Davis RB, Ngo-Metzger Q and Phillips RS: Racial and ethnic disparities in cancer screening. J Gen Intern Med 18: 1028-1035, 2003.

51. Belasco EJ, Gong G, Pence B and Wilkes E: The impact of rural health care accessibility on cancer-related behaviors and outcomes. Appl Health Econ Health Policy 12: 461-470, 2014.

52. Leuven E, Plug E and Rønning M: Education and Cancer Risk, IZA Discussion Paper, No. 7956, 2014. http://www.econstor.eu/ bitstream/10419/93310/1/dp7956.pdf. Accessed July 8, 2014.

53. Parajuli R, Bjerkaas E, Tverdal A, et al: The increased risk of colon cancer due to cigarette smoking may be greater in women than men. Cancer Epidemiol Biomarkers Prev 22: 862-871, 2013. 
54. Hurley S, Goldberg D, Nelson DO, et al: Risk of colorectal cancer associated with active smoking among female teachers. Cancer Causes Control 24: 1291-1304, 2013.

55. Tillmans LS, Vierkant RA, Wang AH, et al: Associations between cigarette smoking, hormone therapy, and folate intake with incident colorectal cancer by TP53 protein expression level in a population-based cohort of older women. Cancer Epidemiol Biomarkers Prev 23: 350-355, 2014.

56. US Department of Health and Human Services. Tobacco use among US racial/ethnic minority groups - African Americans, American indians and Alaska natives, Asian Americans and Pacific islanders, and Hispanics: a report of the surgeon general. National Center for Chronic Disease Prevention and Health Promotion, Office on Smoking and Health. 90, 1998.
57. Fiore MC, Novotny TE, Pierce JP, Hatziandreu EJ, Patel KM and Davis RM: Trends in cigarette smoking in the United States: the changing influence of gender and race. JAMA 261: 49-55, 1989.

58. Novotny TE, Warner KE, Kendrick JS and Remington PL: Smoking by blacks and whites: socioeconomic and demographic differences. Am J Public Health 78: 1187-1189, 1988. 